\title{
Particularități ale cuantificatorilor numelui în româna veche
}

\author{
Camelia Stan* \\ Facultatea de Litere, Universitatea din București, Str. Edgar Quinet 5-7, 010017 București, România \\ Institutul de Lingvistică „Iorgu Iordan - Al. Rosetti”, Calea 13 Septembrie 13, 050711 București, România
}

\section{Despre articol}

Istoric:

Primit 18 mai 2017

Acceptat 4 iunie 2017

Publicat 30 septembrie 2017

Cuvinte-cheie:

gramatică istorică

text biblic

documente vechi

\begin{abstract}
Rezumat
Lucrarea noastră face parte dintr-un studiu colectiv asupra morfologiei istorice a limbii române, elaborat la Institutul de Lingvistică din București al Academiei Române. Analiza de față aprofundează o problemă particulară a evoluției cuantificatorilor numelui, și anume tendința de sudură internă pe care numeralele ordinale compuse au manifestat-o în româna veche, între secolele al XVI-lea și al XVIII-lea. Tendința spre unitate formală a produs modificări morfologice și de comportament sintactic ale numeralelor. Obiectivul urmărit în analiză este acela de a releva și de a explica manifestările morfosintactice ale acestui proces evolutiv. De aceea, formele numeralului sînt discutate prin referire la organizarea sintactică a grupului nominal cuantificat. Cadrul conceptual și metodologic adoptat este cel al teoriei gramaticalizării și al sintaxei diacronice moderne. Cercetarea structurilor vechi care conțin numerale ordinale a condus la observații privind: particularitățile de flexiune și caracterul articulabil al numeralelor ordinale, stadiul de gramaticalizare al formantului al, originea formanților enclitici $-l(u) /-l e /-l e a,-a$, topica formanților.
\end{abstract}

\section{Introducere}

Structurile cuantificate ale grupului nominal erau variate formal în faza veche a limbii române, în perioada care include secolele al XVI-lea, al XVII-lea și al XVIII-lea, pînă în jurul anului 1780, conform delimitărilor temporale larg acceptate în bibliografia românească (pentru periodizarea propusă de Ion Gheție, v. ILRL, p. 52-53; ELR, s.v. veche, limbă ). Textele din acea epocă atestă construcția numelui (în speță, a substantivului) cu diverse tipuri de elemente care au semnificație și funcție cuantificaţională: numerale, adjectivul pronominal toți (cuantificator universal), adjective pronominale cu valoare cuantificațională universală-distributivă (fiecare, fiece etc.), indefinită (atîția, cîțiva, mulți, puţini, unii etc.), negativă (nici un), substantive (precum mulțime, seamă - o seamă de ...) etc.

Particularitățile morfologice și/sau sintactice pe care le aveau în româna veche în special numeralele și adjectivele pronominale au fost permanent în atenția cercetătorilor și sînt discutate în istoriile limbii române (literare) şi în studii speciale, de diverse orientări teoretice, (v., între mulți alții, Densusianu, 1938, p. 177-196, 392-393; Diaconescu, 1970, p. 252-253; Onu, în Rosetti et al., 1971, p. 121, 140, 272, 236, 282, 328; Gheție \& Mareș, 1974, p. 238-240; Rosetti, 1986, p. 498, 500-501; Frâncu, în ILRL, p. 129-131, 331-333; Frâncu, 2009, p. 67-83, 167, 285-295, 347; Ivănescu, 2000, p. 228-229; Todi, 2001, p. 55-57, 253-254; Guruianu, 2005, p. 71-74; Popa, 2007, p. 60-66; Vasiliu, 2007, p. 75-77, 79; Philippide, 2011, p. 452-460; Vieru, 2014, p. 69-75, 84-89; Minuț, 2017, p. 4). Această problematică este tratată de asemenea în studiul lingvistic al unora dintre edițiile filologice ale textelor vechi (v., între alții, Drăganu, 1914, p. 128; Mareș, 1969, p. 81-82; Rizescu, 1971, p. 78-81; Costinescu, 1981, p. 139, 142-143; Buză \& Zgraon, 1982, p. 512-513; Chivu, 1982, p. 190; Chivu, 1993, p. 182-184; Chivu, 2008, p. 54-55; Georgescu, 1982, p. 401; Gheție, 1982, p. 310-311; Gheție \& Teodorescu, 1977, p. 104; Gheție \& Teodorescu, 2005, p. 44; Roman Moraru, 1982, p. 77-78; Tarantino, 1996, p. 172; Dragomir,

\footnotetext{
*Adresă de corespondență: camelia.stan@litere.unibuc.ro.
} 
2006, p. 66-68; Pantaleoni, 2008, p. 75, 77-78; Dima, 2010, p. XXVII; Mazilu, 2012, p. 105-108; Crețu, 2013, p. 223-225; Chiosea, 2016, p. 100-105, 128; Minuț, 2016, p. CLIX-CLXII). Mai recent, particularitățile cuantificatorilor numelui au fost studiate din perspectiva sintaxei diacronice moderne (de exemplu, la Stan, 2013, 2016; Pană Dindelegan, 2016).

Nu vom relua aici observațiile cuprinse în bibliografia menționată și nu vom aborda, în complexitatea ei, problematica particularităților pe care le aveau cuantificatorii numelor în româna veche. Faptele și fenomenele lingvistice în discuție sînt cunoscute.

Ceea ce ne-am propus să examinăm în lucrarea de față este felul în care textele vechi atestă dinamica limbii în limitele perioadei studiate, indiciile pe care textele le oferă cu privire la existența unor tendințe lingvistice în epocă, aspectele relevante din perspectivă evolutivă.

Dintre aspectele dinamicii limbii vechi, ne vom referi aici doar la tendinţa de sudură internă pe care o manifestau numeralele ordinale compuse. Această tendință, ce caracteriza procesul de formare lexicală, s-a manifestat la nivel atît morfologic, cît și sintactic.

Vom considera că numeralele ordinale sînt cuantificatori (ai grupului nominal), deoarece, exprimînd ordinea în numărare, ele implică existența unei pluralități: grupul nominal care include un substantiv şi un numeral ordinal are asociată presupoziția de existență a unei clase (de indivizi) din care face parte referentul substantivului (al doilea copil [„dintre doi sau mai mulți copii”]; presupoziție: „există cel puțin doi copii").

Pentru a realiza obiectivul de cercetare propus, am considerat că este adecvată o comparație între două tipuri stilistice de text vechi: textul biblic și documentul original (administrativ, juridic, privat etc.). Textul biblic vechi este prin excelență conservator, canonic în mod rigid (sub aspect nu doar dogmatic, ci și lingvistic). Documentul original vechi, deși elaborat după anumite modele, oferă totuși materialul poate cel mai apropiat de uzul lingvistic curent din secolele al XVI-lea - al XVIII-lea (uz inaccesibil în mod direct cercetătorilor actuali, în absența unor atestări ale formelor în care se realiza comunicarea spontană în epoca veche).

Principalele traduceri biblice utilizate ca sursă de material în analiza noastră sînt: Vechiul Testament Septuaginta, în versiunea realizată de Nicolae Spătarul Milescu (Ms. 45, BAR Cluj) și publicată recent în ediție filologică, în 2016 (MVTs.1683-1686); comparativ, Biblia de la București (BB.1688, MLD.1688), avînd ca bază a traducerii aceeași versiune greacă a Septuagintei ca și traducerea lui Nicolae Milescu (Munteanu, 2016, p. LXII); Palia de la Orăștie (po.1582) și, comparativ, copia din secolul al XVII-lea a unor cărți din Vechiul Testament, traduse în secolul al XVI-lea pentru Palia de la Orăștie și rămase netipărite în epocă, textul fiind publicat în ediție filologică modernă în 2009 (DVT.1679-1699); Cartea înțelepciunii lui Iisus, feciorul lui Sirah [Cîmpulung Muscel, c. 1665-1672], text editat în 2005 (Cî́r S.1655-1672).

Documentele utilizate ca sursă de material pentru secolul al XVI-lea sînt cele din corpusul Dî. Pentru secolele al XVII-lea și al XVIII-lea, am utilizat documente publicate recent, mai puțin studiate sau complet inedite pentru cercetarea lingvistică; acestea sînt: CATASTIFE.1744-1745, CATASTIH.1732, CONDICĂ.1748-1751, DOC.ATHOS, DOC.DRAGOMIRNA, DOC.ŢR (vol. I-II).

\section{Forme și utilizări ale numeralelor ordinale compuse}

În româna veche, forma și proprietățile sintactice ale numeralelor ordinale compuse nu erau fixate. Aspectele relevante în perspectivă evolutivă sînt: variația formanților $-l /-l e /-l e a$; absența formanților $-l /-l e /$ $-l e a,-a$; topica formanților; marcarea cazurilor genitiv-dativ; tendința de pierdere a flexiunii; construcția cu cel și de.

\subsection{Variația și absența formanților $-l /-l e /-l e a,-a$}

2.1.1. Densusianu (1938, p. 179) a arătat că, la numeralele ordinale compuse cu al, forma de masculin avînd finala -le, precum al doile (Psaltirea Hurmuzaki), era mai frecventă, în secolul al XVI-lea, decît forma în -lea, care conține după -le- elementul final -a: al doilea (Cazania I a lui Coresi). Densusianu 
a înregistrat în texte din aceeași perioadă și formele de masculin în -l: al optul (de exemplu, în Codicele Voronețean), al patrul (în Tetraevanghelul lui Coresi etc.).

Concurența formelor cu și fără particula finală deictică $-a$ este discutată și în studiul lingvistic al edițiilor filologice de text (v., între mulți alții, Mareș, 1969, p. 82; Chivu, 1993, p. 184; recent, Minuț, 2016, p. CLXI).

Într-o lucrare anterioară (Stan, 2016, p. 349), am prezentat rezultatul unei analize privind numărul de ocurențe ale formelor vechi, în -le, și ale formelor noi, în -lea. Analiza a relevat prezența ambelor tipuri de forme în traducerile și în documentele originale din secolul al XVI-lea (documente care formează corpusul Dî). Proporția este în favoarea formelor vechi în traduceri și în favoarea formelor noi în documente. Formele vechi în -l al optul și al patrul au fost înregistrate în texte religioase din secolul al XVI-lea și din prima jumătate a secolului al XVII-lea; forma al patrul apare și în corpusul Dî.

2.1.2. Un fapt interesant este absența formanților enclitici ai numeralelor ordinale compuse cu al în notația cifrică: la masculin, lipsește formantul -le/-lea în (1a), iar la feminin, formantul - a în (1b,c). După demonstrativul cel, numeralele au însă formanți enclitici: formantul - $a$ la feminin, în notația literală (1d); formantul $-l$ la masculin, în notația cifrică (1e).

(1) a. al 2 tîlcu (DvT.1679-1699, tîlc la Daniil, 2, f. 288 );

b. a 5 manorchie [...] a 4 mai bună putere (DVT.1679-1699, tîlc la Daniil, 2, f. 288v');

c. a 4 jivină (DVT.1679-1699, Daniil, 7, 7, f. 299);

d. cea a patra jivină (DVT.1679-1699, Daniil, 7, 23, f. 300v);

e. cel al 4-l (DVT.1679-1699, Daniil, 3, 92, 25, f. 292v).

Prezența formantului enclitic $-l$ al numeralelor ordinale în construcțiile cu determinantul [+ definit, + deictic] $c e l$ capătă relevanță, dacă admitem că $-l$ din structura numeralelor ordinale vechi ar fi legat etimologic de articolul definit enclitic $-l$ (pentru asocierea etimologică dintre formantul enclitic - $l u,-l e$ din structura numeralului ordinal masculin și articolul definit enclitic, v. ILR (II, p. 237-238); Rosetti (1986, p. 373). În formele de feminin, a patra (1d), elementul enclitic - $a$ corespunde formantului $-l$ sau $-l e$, dar și particulei deictice $-a$, din formele de masculin. Coocurența cu $c e l$ a formantului enclitic $-l$ în (1e) ar putea fi astfel pusă în legătură cu trăsăturile lor comune. Nu avem certitudinea că, pentru vorbitorii din epoca veche, $-l$ exprima definitudinea în numeralele al optul, al patrul; orice interpretare semantică în această privință este imposibil de documentat cu fapte și, deci, este speculativă, excesivă. Formațiile al optul, al patrul sînt însă foarte asemănătoare cu substantivele masculine articulate cu articolul definit enclitic $-l$. De aceea nu putem exclude analogia cu articolul definit. Numeralele ordinale compuse cu al au definitudinea ca trăsătură intrinsecă, deoarece al încorporează etimologic articolul definit (pentru explicația etimologică, v. DELR, s.v. al și bibliografia). Cel de asemenea încorporează etimologic articolul definit (DELR, s.v. acel, cel și bibliografia). Astfel, selecția formantului enclitic al numeralului ordinal în structurile cu determinantul [+ definit, + deictic] cel va fi avut, probabil, o bază etimologică.

Un aspect relevant pentru distribuția formantului enclitic $-a$, de la feminin, apare la Nicolae Milescu (MVTs.1683-1686). Minuț (2016, p. CLXI) a arătat că numeralele ordinale feminine cu baza 11-19 sînt utilizate (în notație literală) cu sau fără particula finală $-a$. Parcurgerea exemplelor citate de autoare și a altor exemple din textul Spătarului Milescu sugerează însă că variația era, într-o anumită măsură, dependentă de contextul sintactic. Se poate remarca o preferință pentru formele cu $-a$ înaintea unui nume feminin nearticulat $(2 \mathrm{a}, \mathrm{b}) ;-a$ putea lipsi după un substantiv feminin articulat cu articolul enclitic $-a(2 c, d)$. Distribuția formelor nu este însă consecventă (2e). Distribuția formantului enclitic $-a$ în $(2 a-$ d) este similară distribuției articolului enclitic din tiparele grupului nominal care s-au impus în româna modernă: articolul definit se atașează totdeauna primului constituent al grupului nominal, adică numelui sau adjectivului antepus (luna următoare, următoarea lună). Similar, particula deictică $-a$ este atașată numeralului ordinal antepus $(2 \mathrm{a}, \mathrm{b})$, dar este absentă din forma numeralului după un nume articulat definit cu articolul enclitic $-a(2 c, d)$. 
(2) a. în doaosprădzêcea lună (MVTs.1683-1686, Est, 9, 1, p. 420; lipsește a(l), marca numeralului ordinal);

b. în a treisprăzêcea a al doaosprăzêcea lună (MVTs.1683-1686, 2Mac, 15, 37, p. 881);

c. în dzua a doaosprădzêce (MVTs.1683-1686, Num, 7, 78, p. 125);

d. întru luna a doaosprăzêce (MVTs.1683-1686, Iez, 32, 1, p. 653);

e. în a patrusprădzêce $d z i$ (MVTs.1683-1686, Ieș, 18, p. 62; lipsește - a final înaintea numelui nearticulat).

Și unele numerale decimale feminine apar fără - $a$ final înaintea numelui nearticulat:

(3) întru a cincidzeci sărbătoare (MVTs.1683-1686, Tovit, 2, 2, p. 728).

De asemenea, formantul -lea putea lipsi în notația literală:

(4) anul al optsprădzêce (MVTs.1683-1686, Ier, 32, 1, p. 600).

În DVT.1679-1699, numeralele notate prin cifre, fără formant final, apar atît în partea tradusă a textului biblic (1c), cît și în părțile care conțin tîlcul (1a,b).

Absența formanților finali ai numeralelor ordinale notate prin cifre poate fi observată în cărțile rămase netipărite ale Paliei (DVT.1679-1699), dar și în Palia tipărită (po.1582). Faptul a fost remarcat de Vieru (2014, p. 71), cu referire la Palie; autoarea a arătat că acolo unde numeralele ordinale sînt notate prin cifre formanții -le/-lea nu sînt notați (5).

(5) a. născu lui Iacov al 6 ficior (Po.1582, Bit, 30, 19, p. 101);

b. în al 13 ani [...] în al 14 an (po.1582, Bit, 14, 4-5, p. 48).

În DVT.1679-1699, formantul final - $l$ apare însă după notaţia cifrică (1e).

Absența formanților finali ai numeralelor ordinale compuse cu al, în cărțile Paliei (po.1582, DVT.16791699) nu este o pură simplificare a notației cifrice. Acest tip de notație conține totdeauna formantul al, iar formantul enclitic este în general absent. Credem că acest fapt sugerează o diferență între formanţi în ceea ce privește gradul lor de sudură în interiorul compusului, în notația cifrică: textul reflectă un stadiu de limbă în care exista un grad mai avansat de sudură între al și baza compusului (numeralul cardinal încorporat ca bază a numeralului ordinal compus și redat prin cifră), decît între formanții enclitici și bază. $A l$ funcționa deja ca o marcă a numeralului ordinal (comparativ cu numeralul cardinal) și, ca atare, era neomisibil în notațiile cifrice. $A l$ era un element complet funcțional, gramaticalizat, specializat ca marcă a numeralului ordinal. Este posibil ca, în anumite situații, să fi existat un raport de redundanță între formanții enclitici și al: mai ales în notațiile cifrice de tipul (1a,b,c), (5), în care al este variabil și marchează prin forma sa (al, masculin; $a$, feminin) distincția flexionară de gen masculin/feminin a numeralului, mărcile enclitice $-l /-l e /-l e a$ (masculin), $-a$ (feminin) marcau suplimentar, redundant distincția de gen și, prin urmare, puteau fi suprimate.

Notațiile de tipul al 2 (1a) sînt rare în documentele originale (6) și nu mai sînt posibile în limba actuală.

(6) a 5 fată Marie (Dî,, Maramureș, p. 205).

Prezența lui al în notațiile cifrice utilizate în stilul biblic din secolul al XVI-lea, stil prin excelență conservator, atestă indirect faptul că gramaticalizarea lui al în numeralul ordinal se încheiase într-o perioadă mai veche.

Textele din secolul al XVI-lea nu atestă fenomene de variație a formei numeralelor ordinale decît cu privire la formanții enclitici. 


\subsection{Topica formanților}

Densusianu (1938, p. 180) a înregistrat, în traducerile din secolul al XVI-lea, forme feminine ale numeralelor ordinale de tipul a dooasprădzece (Psaltirea Voronețeană), cu formantul - $a$ atașat nu în encliză, la finalul compusului [(2a): doaosprădzêcea], ci după primul constituent al acestuia (doo).

Astfel de forme apar și în texte mai tîrzii. Prezența acestor formații în textele biblice este discutată, mai recent, de Popa (2007, p. 66), cu referire la cartea Faptele Apostolilor din Noul Testament de la Bălgrad, 1648 (de exemplu, a patrasprăzeace), în comparație cu Biblia de la București, 1688 (a patrusprăzeace, fără $-a$ final).

Structura (7a) atestă o situație complexă, în care topica formantului -lea perturbă proprietățile sintactice ale numeralului.

(7) a. acesta al patruzecilea și cinci de ani (вв.1688, Iisus Navi, 14, 10, p. 163);

b. acesta [OrdP [OrdP al patruzecilea] [CardP și cinci [de ani]]] $]^{1}$.

În numeralul ordinal cu baza patruzeci și cinci, formantul masculin -lea este ataşat primului component. Forma al patruzecilea are structură de numeral ordinal. Componentele şi cinci alcătuiesc o grupare ce corespunde părții finale din structura numeralului cardinal. Gruparea şi cinci asociază formației al patruzecilea și cinci proprietăți sintactice de numeral cardinal patruzeci şi cinci. Așa se explică atașarea prin de a numelui cuantificat, ani (analog construcției numeralului cardinal: patruzeci și cinci de ani). Numeralul ordinal al patruzecilea și cinci are o structură internă anacolutică, reprezentată în (7b). Al doilea anacolut constă în lipsa acordului de număr în interiorul grupului nominal: determinantul demonstrativ acesta și numeralul ordinal al patruzecilea au formă de singular, iar numele ani are formă de plural (cerută de numeralul cardinal patruzeci și cinci, bază a numeralului ordinal anacolutic al patruzecilea şi cinci).

În structura (8), topica formantului -lea este similară celei din (7a):

(8) anul al doaodzecilea șipatru (мvтs.1683-1686, 3Reg, 15, 8, p. 302).

În (9), formantul -lea este ataşat primului constituent, într-o formație anacolutică bazată pe inversiune, iar numele ai este atașat prin prepoziția de:

(9) întru al şaptelea şi doadzeci de ai (MVTs.1683-1686, Iez, 29, 17, p. 651).

Plasarea formanților specifici ai numeralului ordinal -lea, $-a$ în interiorul compusului atestă un grad mai mic de sudură internă a numeralului. Formațiile cu -lea, - a plasate enclitic au un grad mai mare de sudură internă, sînt generale în documentele originale, încă din secolul al XVI-lea (al doozecilea, Dî.1599, p. 115) și s-au impus în limbă.

\subsection{Flexiunea: marcarea cazurilor genitiv-dativ; tendința de pierdere a flexiunii}

2.3.1. În grupul nominal care include un numeral ordinal, cazul genitiv-dativ putea fi marcat o singură dată, în forma numelui (10a) sau putea fi marcat redundant, prin morfeme enclitice atașate numelui și numeralului antepus (10b); recent, Vieru (2014, p. 72) a discutat structurile din Palia de la Orăştie:

(10) a. în dzi dentîi al zeace luniei (Po.1582, Bit, 8, 5, p. 32);

b. alșeptei luniei (Po.1582, Bit, 8, 4, p. 32).

Cazul numeralului este marcat, în (10b), prin atașarea formei de genitiv-dativ a articolului enclitic.

Tiparul care s-a impus în limbă este acela în care cazul numeralului ordinal este marcat prin forma cazuală a determinantului $c e l$, antepus:

\footnotetext{
${ }^{1}$ În reprezentarea structurii sintactice $(7 \mathrm{~b})$, am utilizat convențiile de formalizare ale gramaticii generative: am delimitat prin paranteze drepte grupurile sintactice; am notat prin simbolul CardP grupul sintactic al numeralului cardinal (engl. cardinal phrase), iar prin simbolul OrdP, grupul sintactic al numeralului ordinal (engl. ordinal phrase).
} 
(11) celui al patrulea (Ĉ̂Ifs.1655-1672, Iisus Sirah, 26, 5, f. 326r ).

Opțiunea unor autori tîrzii, precum Stolnicul Constantin Cantacuzino, pentru formele vechi, articulate enclitic, ale numeralului ordinal la genitiv-dativ, în defavoarea formelor noi, cu cel, se explică prin aceea că formele vechi erau marcate stilistic, arhaizau textul și caracterizau registrul cult:

(12) a. într-a treia decadă $\boldsymbol{a} a$ doauăi cărți a lui (cIst.1700-1750, f. 24 $4^{\mathrm{r}}$ );

b. într-a doua decadă a a patrai cărți (CIst.1700-1750, f. 30 $30^{\mathrm{r}}$ ).

Structurile cu cel caracterizau în epoca veche, ca și astăzi, un stil îngrijit, elaborat. Ele nu sînt caracteristice pentru documentele administrative conținute în corpusurile CATASTIFE.1744-1745, CATASTIH.1732, CONDICĂ.1748-1751, DOC.ATHOS, DOC.DRAGOMIRNA, DOC.ȚR (vol. I-II).

2.3.2. Structurile cu grupul nominal nonmarcat la cazul genitiv-dativ se explică, în traduceri, prin influența greacă. Exemplele apar la Nicolae Milescu (Minuț, 2016, p. CLXII), nu doar în textele biblice (13), ci și în alte traduceri ale autorului (14):

(13) numele al doilea rîu (MVTs.1683-1686, Fac, 2, 13, p. 3; 'celui de al doilea rîu');

(14) svîrșitul al doile cuvînt (ICP 1700, f. 141' ${ }^{\mathrm{r}}$; 'celei de a doua orații').

Tiparul nu este însă caracteristic traducerilor de altă factură stilistică, precum Epistolă și panegiric grecoromân adresate lui Constantin Brîncoveanu (Ms. BAR 766), text publicat recent în ediție filologică modernă (EP.1692-1697).

2.3.3. Formele vechi de plural ale numeralului ordinal: ai treii (Densusianu, 1938, p. 179), cu numărul marcat în forma flexionară a elementului funcțional al și în forma articolului enclitic atașat numeralului, nu s-au păstrat în limbă. Pierderea distincțiilor flexionare de număr, fixarea numeralului ordinal în forme invariabile de singular, se corelează cu creșterea unității sale formale.

\subsection{Construcția cu cel și de}

Numeralul ordinal întîi din structurile cu cel era utilizat în forma dintîi compusă cu prepoziția de (Densusianu, 1938, p. 179):

(15) cea dintîie (DVT.1679-1699, Daniil, 7, 4, f. 299v).

La numeralele ordinale compuse cu al, structurile cu de (care s-au fixat în limbă): cel de al doilea și structurile fără de (11), (16) au fost în variație pe toată durata epocii vechi.

(16) a. cel al triilea (MVTs.1683-1686, Iosip, 10, 1, p. 900);

b. cel al treilea (MLD.1688, Iosip, 10, 1, p. 54).

Structurile cu de erau mai puțin sudate în limba veche decît astăzi, fapt relevat de însăși variația cu structurile fără $d e$, adică de posibilitatea alegerii între cele două construcții. În limba actuală, structura cu de are o anumită unitate formală, de fiind neomisibil în prezența lui cel. Prepoziția de nu este sudată însă cu numeralul, ca în cazul compusului dintîi. 


\section{Concluzii}

Analiza noastră a pus în evidență unele aspecte ale tendinței de sudură internă a numeralelor ordinale, în româna veche.

Cercetarea s-a bazat pe un material faptic extras din cîteva traduceri biblice și din documente originale, netraduse. Textele biblice examinate (din secolele al XVI-lea și al XVII-lea) conțin forme și structuri vechi, unele probabil anacronice în perioada respectivă, care nu apar în documentele mai apropiate de uzul lingvistic curent. Documentele originale au constituit un reper al analizei. Comparaţia dintre limbajul biblic conservator și limba documentelor a permis observarea unor aspecte evolutive în comportamentul gramatical al numeralelor ordinale.

Sursele analizate oferă sugestii interesante pentru redeschiderea unor probleme precum: stadiul de gramaticalizare în care se afla marca al a numeralului ordinal la începutul epocii vechi, originea formanților enclitici $-l(u) /-l e /-l e a,-a$ din structura numeralului ordinal.

Analiza a condus și la cîteva observații de detaliu privind topica formanților și flexiunea numeralului ordinal, caracterul articulabil al acestuia în limba veche.

În documentele originale vechi, numeralele ordinale sînt utilizate extrem de limitat, valorile numerice fiind exprimate, în general, prin numerale cardinale.

\section{Bibliografie}

\section{A. Corpus}

вв.1688 = Biblia adecă Dumnezeiasca Scriptură a Vechiului și Noului Testament, tipărită întîia oară la 1688 în timpul lui Șerban Vodă Cantacuzino, Domnul Țării Românești, Editura Institutului Biblic, București, 1977.

CATASTIFE.1744-1745 = Lazăr, G. (ed.) (2015). 8 documente, în Iacob, D.D. (ed.), Avere, prestigiu și cultură materială în surse patrimoniale. Inventare de averi din secolele XVI-XIX, Editura Universității „Alexandru Ioan Cuza”, Iași, p. 488-521.

CATASTIH.1732 = Bedreag, E. (ed.) (2015). Document [BAR, Documente istorice, nr. 1129/126, orig. rom., 38 de file], în Iacob, D.D. (ed.), Avere, prestigiu și cultură materială in surse patrimoniale. Inventare de averi din secolele XVI-XIX, Editura Universităţii „Alexandru Ioan Cuza”, Iași, p. 166-200.

CIst.1700-1750 = Stolnicul C. Cantacuzino, Istoriia Țărîi Rumânești [1700-1750; v. SOR, p. 641], ed. O. Dragomir, Editura Academiei Române, București, 2016.

Cîrrs.1655-1672 = Bălan-Mihailovici, A. (ed.) (2005). Cartea înțtelepciunii lui Iisus, feciorul lui Sirah [Cîmpulung Muscel, c. 1665-1672], Editura Sinergii, Cîmpulung Muscel.

CONDICĂ.1748-1751 = Mârza, M. (ed.) (2015). Document [Arhivele Naționale din Iași, Manuscrise, nr. 1705, 34 de file], în Iacob, D. D. (ed.), Avere, prestigiu și cultură materială în surse patrimoniale. Inventare de averi din secolele XVI-XIX, Editura Universității „Alexandru Ioan Cuza”, Iași, p. 216-251.

Dî = Mareș, Al. et al. (1979). Documente şi însemnări româneşti din secolul al XVI-lea, Editura Academiei Române, București. DOC.ATHOS = Zahariuc, P. \& Marinescu, Fl. (eds) (2010). Documente româneşti din arbiva Mănăstirii Xenofon de la Muntele Athos, Editura Universității „Alexandru Ioan Cuza”, Iași, p. 51-103.

DOC.DRAGomiRnA = Iufu, I. \& Brătulescu, V. (eds) (2012). Manuscrise slavo-române din Moldova. Fondul Mănăstirii Dragomirna, Editura Universității „Alexandru Ioan Cuza”, Iaşi.

DOC.ȚR = Lazăr, G. (ed.) (2013-2014). Documente privitoare la negustorii din Țara Românească, I: 1656-1688; II: 16891714, Editura Universităţii „Alexandru Ioan Cuza”, Iași.

DVT.1679-1699 = Dima, C.-I. (2009). O traducere inedită a Vechiului Testament din secolul al XVI-lea [Crișana, Bihor, 1679_ 1699; ms. rom. 130, BAR], Editura Universității din București, București.

EP.1692-1697 = Chiosea, S. (ed.) (2016). Epistolă și panegiric greco-român adresate lui Constantin Brîncoveanu (Ms. BAR 766), Editura Universităţii „Alexandru Ioan Cuza”, Iaşi.

ICP 1700 = Ioan Cantacuzino, Patru apologii pentru religia creștinăși Patru orații. Traduse în limba română la mijlocul secolului al XVII-lea de Nicolae Spătarul (Milescu), ed. E. Dima, Editura Universității „Alexandru Ioan Cuza”, Iași, 2010.

MLD.1688 = Munteanu, E. (coord.) (2012). Monumenta linguae Dacoromanorum. Biblia 1688. Pars XXII, Iosephus ad Machabaeos, Editura Universităţii „Alexandru Ioan Cuza”, Iaşi.

MVTs.1683-1686 = Munteanu, E. (coord) (2016). Vechiul Testament - Septuaginta, Versiunea lui N. Spătarul Milescu [16831686] (Ms. 45, BAR Cluj), Editura Universității „Alexandru Ioan Cuza”, Iaşi.

po.1582 = Pamfil, V. (ed.) (1968). Palia de la Orăștie, Editura Academiei Române, București. 


\section{B. Referințe}

Arvinte, V. (2006). Calcuri lingvistice în cartea Ieșirea (PO, BB, ms. 45, ms. 4389), în Arvinte, V., Studii de istorie a limbii române, Editura Universității „Alexandru Ioan Cuza”, Iași, p. 459-462 [publicat anterior în ALIL, vol. XXXII, 1988-1991, p. 25-28].

Buză, E. \& Zgraon, F. (1982). Studiu lingvistic la Prefețe și epiloguri din secolul al XVI-lea, în TR, p. 487-548.

Chiosea, S. (2016). Studiu lingvistic, în Chiosea, S. (ed.), Epistolă și panegiric greco-român adresate lui Constantin Brîncoveanu (Ms. BAR 766), Editura Universității „Alexandru Ioan Cuza”, Iași, p. 43-212.

Chivu, Gh. (1982). Studiu lingvistic la Pravila lui Coresi [Braşov, c. 1560-1562], în TR, p. 162-212.

Chivu, Gh. (1993). Studiu lingvistic, în Chivu, Gh. (ed.), Codex Sturdzanus [c. 1583-1619], Editura Academiei Române, București, p. 142-230.

Chivu, Gh. (2008). Studiu lingvistic, în Chivu, Gh. (ed)., Dictionarium valachico-latinum [Anonymus Caransebesiensis, 1650], Editura Academiei Române, București, p. 36-62.

Costinescu, M. (1981). Studiu lingvistic, în Costinescu, M. (ed.), Codicele Voronețean [1563-1583], Editura Minerva, București, p. 89-213.

Crețu, C. (2013). Studiu lingvistic, în Ilie Miniat, Cazanii (București, 1742), ed. C. Crețu, Editura Universității „Alexandru Ioan Cuza”, Iași, p. 129-268.

DELR = Sala, M. \& Avram, A. (coord.) (2011-2015). Dicționarul etimologic al limbii române, I-II, Editura Academiei Române, București.

Densusianu, O. (1938). Histoire de la langue roumaine, II, Librairie E. Leroux, Paris.

Diaconescu, P. (1970). Structură şi evoluție in morfologia substantivului românesc, Editura Academiei Române, București.

Dima, E. (2010). Studiu introductiv, în Ioan Cantacuzino, Patru apologii pentru religia creștină și Patru orațiii. Traduse în limba română la mijlocul secolului al XVII-lea de Nicolae Spătarul (Milescu), ed. E. Dima, Editura Universităţii „Alexandru Ioan Cuza", Iași, p. VII-XLIX.

Dragomir, O. (2006). Studiu lingvistic, în Dragomir, O. (ed.), Istoriia Țărîi Rumânești atribuită stolnicului Constantin Cantacuzino, Editura Academiei Române, București, p. 39-135.

Drăganu, N. (1914). Particularitățile de limbă ale Codicelui Todorescu, în Drăganu, N. (ed.), Două manuscripte vechi: Codicele Todorescu și Codicele Marțian, Librăriile Socec și C. Sfetea, București, p. 89-166.

ELR = Sala, M. (ed.) (2001). Enciclopedia limbii române, Editura Univers Enciclopedic, București.

Frâncu, C. (2009). Gramatica limbii române vechi (1521-1780), Casa Editorială Demiurg, Iași.

Georgescu, M. (1982). Studiu lingvistic la Glosele Bogdan, în TR, p. 385-417.

Gheție, I. (1982). Studiu lingvistic la Fragmentul Todorescu [Cluj, c. 1571-1575], în TR, p. 285-331.

Gheție, I. \& Mareș, Al. (1974). Graiurile dacoromâne în secolul al XVI-lea, Editura Academiei Române, București.

Gheție, I. \& Mareș, Al. (1985). Originile scrisului în limba română, Editura Științifică și Enciclopedică, București.

Gheție, I. \& Teodorescu, M. (1977). Studiu de limbă, în Gheție, I. \& Teodorescu, M. (eds), Manuscrisul de la Ieud, Editura Academiei Române, București, p. 59-141.

Gheție, I. \& Teodorescu, M. (2005). Studiu lingvistic, în Gheție, I. \& Teodorescu, M. (eds), Psaltirea Hurmuzaki, I, Editura Academiei Române, București, p. 23-75.

Guruianu, V. (2005). Sintaxa textelor românești originale din secolul al XVI-lea. Sintaxa propoziției, Editura Universității din București. [București].

ILR = Coteanu, I. (ed.) (1969). Istoria limbii române, II, Editura Academiei Române, București.

ILRL = Gheție, I. (ed.) (1997). Istoria limbii române literare. Epoca veche (1532-1780), Editura Academiei Române, București.

Ivănescu, G. (2000). Istoria limbii române, ed. a II-a [ed. I: 1980], Editura Junimea, Iași.

Mareș, Al. (1969). Studiu de limbă, în Mareș, Al. (ed.), Liturghierul lui Coresi [Brașov, 1570], Editura Academiei Române, București, p. 47-118.

Mazilu, I. (2012). Studiu lingvistic, în [Eustratie logofătul], Șeapte taine a besearecii, Iași, 1644, ed. I. Mazilu, Editura Universității „Alexandru Ioan Cuza”, Iași, p. 41-159.

Minuţ, A.-M. (2016). Studiu asupra morfologiei din Ms. 45, în MVTs.1683-1686, p. CXIII-CCIX.

Minuț, A.-M. (2017). Elemente de morfologie istorică românească, pe baza primei traduceri in limba românăa Septuagintei (ms. 45, BAR Cluj), în „Diacronia”, nr. 5, 23 mart., art. A66, Crossref.

Munteanu, E. (2016). Studiu filologic, în MVTs.1683-1686, p. XLI-LXXVII.

Pană Dindelegan, G. (2016). The partitive phrase, în soR, p. 323-332, Crossref.

Pantaleoni, D. (2008). Morfologia, în Pantaleoni, D. (ed.), Texte românești vechi cu alfabet latin: Psalterium Hungaricum în traducere anonimă din secolul al XVII-lea, Editura Universității de Vest, [Timişoara], p. 73-78.

Philippide, Al. (2011). Istoria limbii române [versiunea manuscrisă, 1893-1932], ed. G. Ivănescu, C.-G. Pamfil, L. Botoșineanu, Editura Polirom, [Iaşi].

Popa, E.-C. (2007). Studiu lingvistic asupra cărțtii Faptele Apostolilor din Biblia de la București (1688) in comparație cu Noul Testament de la Bălgrad (1648) și cu Biblia de la Blaj (1795), Casa Editorială Demiurg, Iași. 
Rizescu, I. (1971). Studiu de limbă, în Rizescu, I. (ed.), Pravila ritorului Lucaci [1581], Editura Academiei Române, București, p. 35-145.

Roman Moraru, A. (1982). Studiu lingvistic la Catehismul lui Coresi [Brașov, c. 1560], în TR, p. 56-97.

Rosetti, A. (1986). Istoria limbii române, I. De la origini până la începutul secolului al XVII-lea, ediție definitivă [ed. I: 1938], Editura Științifică și Enciclopedică, [București].

Rosetti, A., Cazacu, B. \& Onu, L. (1971). Istoria limbii române literare, ed. a II-a, Editura Minerva, București.

sor = Pană Dindelegan, G. (ed.) (2016). The Syntax of Old Romanian, Oxford University Press, Oxford, Crossref.

Stan, C. (2013). O sintaxă diacronică a limbii române vechi, Editura Universității din București, București.

Stan, C. (2016). (Numerical and non-numerical) quantifiers; quantifying approximators, în sor, p. 346-356, Crossref.

Tarantino, A. (1996). Le strutture linguistiche, în Tarantino, A. (ed.), La storia di Filerot e Anthusa. Istoria lui Filerot și cu a Anthusei (ms. 1374, BAR - Bucarest), Bagatto Libri, Roma, p. 115-187.

Todi, A. (2001). Elemente de sintaxă românească veche, Editura Paralela 45, Pitești/București/Brașov/Cluj-Napoca.

TR = Gheție, I. (coord.) (1982). Texte românești din secolul al XVI-lea, Editura Academiei Române, București.

Vasiliu, L. (2007). Atributul, în Avram, M. (ed.), Sintaxa limbii române în secolele al XVI-lea - al XVIII-lea, Editura Academiei Române, București, p. 73-109.

Vieru, R. (2014). Studiu lingvistic asupra Paliei de la Orăştie, Editura Universității „Alexandru Ioan Cuza”, Iași. 